\title{
EL COMPONENTE EVALUATIVO EN NARRACIONES DE PERSONAS CON ESQUIZOFRENIA Y PSICOSIS AFECTIVA*
}

\author{
ALICIA FIGUEROA BARRA \\ Universidad de Chile
}

\begin{abstract}
¿Por qué nos representamos a nosotros mismos mediante el relato, de un modo tan natural que nuestra identidad parece ser un producto de nuestros relatos?
\end{abstract}

(J. Bruner, 2003)

\section{RESUMEN}

En el presente estudio nos proponemos describir algunos aspectos de las narraciones de personas con diagnóstico de esquizofrenia y de psicosis afectiva crónica y de primer episodio enmarcadas en la entrevista clínica que constituye el instrumento más relevante para la indagación psiquiátrica (Labov y Fanshel, 1977; Mischler, 1986; Lewis, 2011). Por una parte, se valoró el desempeño comunicativo en la evaluación de la narración y, por otra, se analizaron los recursos narrativos en ambas patologías y, específicamente, el empleo de estrategias para la evaluación del relato (Labov y Waletsky, 1967; Labov, 1985; Mandler y Johnson, 1977; Graesser, 1981; Kintsch y Van Dijk, 1983; Bruner, 1984, 2006; Schegloff, 1997 y Bassols y Torrent, 2003). Nuestro objetivo general fue determinar las diferencias en el componente evaluativo de las narraciones entre los grupos de pacientes. A su vez, el objetivo específico fue establecer la posible relación entre diagnóstico clínico, el estadio de la enfermedad, el sexo y los fenómenos discursivos estudiados. La hipótesis del estudio sostiene que hay un peor desempeño en el componente evaluativo de la historia entre personas con diagnóstico de esquizofrenia en comparación con las que padecen psicosis afectiva. Asimismo, en la esquizofrenia las dificultades en la elaboración de narraciones serían un marcador de déficit por aparecer desde el primer episodio. Para tales propósitos se analizaron 75 entrevistas de sujetos chilenos con los siguientes diagnósticos: 25 perso-

* El presente artículo es parte del proyecto LEPSI, Lenguaje, Psicosis e Intersubjetividad de la Unidad de Psicolingüística clínica del Depto. de Psiquiatría y Salud Mental Campus Sur de la Facultad de Medicina de la Universidad de Chile.

Prof. Dra. Alicia Figueroa Barra, investigadora de Unidad de Psicolingüística Clínica, Departamento de Psiquiatría y Salud Mental, Campus Sur, Facultad de Medicina, Universidad de Chile. Dra. en Lingüística <aliciafigueroa@med.uchile.cl>. 
nas con esquizofrenia crónica, 25 de primer episodio de esquizofrenia y 25 con psicosis afectiva, constituyendo una muestra representativa de ambas patologías.

PALABRAS CLAVE: narración, componente evaluativo, esquizofrenia, psicosis afectiva.

\section{ABSTRACT}

In the present study, we propose to describe some aspects of the narratives of people diagnosed with schizophrenia and chronic affective and first-episode psychosis as part of the clinical interview, which is the most relevant instrument for psychiatric inquiry (Labov and Fanshel, 1977; Mischler, 1986; Lewis, 2011). On the one hand, the communicative performance was evaluated in the evaluation of the narration and, on the other hand, the narrative resources in both pathologies were analyzed and, specifically, the use of strategies for the evaluation of the narrative (Labov and Waletsky, 1967; Mandler and Johnson, 1977; Graesser, 1981; Kintsch and Van Dijk, 1983; Bruner, 1984, 2006; Schegloff, 1997, and Bassols and Torrent, 2003). Our overall objective was to determine the differences in the evaluative component of narratives among patient groups. At the same time, the specific objective was to establish the possible relationship between clinical diagnosis, the stage of disease, sex and the discursive phenomena studied. The study hypothesis holds that there is a worse performance in the evaluative component of the history between people diagnosed with schizophrenia compared to those with affective psychosis. Also, in schizophrenia the difficulties in the elaboration of narrations would be a marker of deficit to appear in the first episode. For these purposes, 75 interviews of Chilean subjects with the following diagnoses were analyzed: 25 people with chronic schizophrenia, 25 with first episode of schizophrenia and 25 with affective psychosis, constituting a representative sample of both pathologies.

KEYWORDS: narration, evaluative component, schizophrenia, affective psychosis.

\section{INTRODUCCIÓN}

Durante las últimas décadas se ha desarrollado un vasto campo de investigación en torno a la narración como género discursivo. Existe una considerable cantidad de modelos para el análisis de las narraciones desde diferentes corrientes teóricas; tal es el caso de los estudios sobre las narraciones de experiencia personal de Labov y Waletsky (1967), las gramáticas de las historias de Rumelhart (1975) y de Mandler y Johnson (1977); el enfoque cognitivo de Graesser (1981); Kintsch y Van Dijk (1983); Bruner (1984); Berman y Slobin (1994), entre muchos otros especialistas en el tema. Actualmente, la interfaz dada por la Lingüística Clínica funcional y la psiquiatría se transformó en una variable mediadora entre la neurocognición y el comportamiento social de las personas que padecen enfermeda- 
des mentales. La estrecha relación entre lenguaje y psiquiatría permite una aproximación holística de manera equivalente tanto a los fenómenos lingüístico-comunicativos como a los fenómenos clínicos, favoreciendo el diagnóstico diferencial y la comprensión integrada de enfermedades como la esquizofrenia o las psicosis afectivas (Morice e Ingram, 1983; Laguna y Turull, 2000; De Lisi, 2001; Salavera y Puyuelo, 2010; Gallardo-Paúls y Hernández, 2013; Figueroa, 2015). Las conclusiones difundidas en estos trabajos son ampliamente aceptadas y se han utilizado para interpretar numerosos fenómenos cognitivo-discursivos que inciden en las patologías mencionadas.

La propuesta de trabajo para esta investigación consiste en la descripción de algunos aspectos narrativos en personas con los siguientes diagnósticos: esquizofrenia y psicosis afectiva, en etapa crónica y en primer episodio. Dichas pesquisas se enmarcaron en el contexto de la entrevista clínica, que es sin duda, la herramienta central para la exploración psiquiátrica (Labov y Fanshel, 1977; Mischler, 1986; Lewis, 2011). Por una parte, se valoró el nivel de desempeño del componente evaluativo de la narración y, por otra, se analizaron los recursos narrativos en ambas patologías y, específicamente, el empleo de estrategias para la evaluación del relato (Labov y Waletsky, 1967; Labov, 1985; Mandler y Johnson, 1977; Graesser, 1981; Kintsch y Van Dijk, 1983; Bruner, 1984, 2006; Schegloff, 1997 y Bassols y Torrent, 2003). Nuestro objetivo general fue determinar las diferencias del componente evaluativo de las narraciones entre los grupos de pacientes. A su vez, el objetivo específico fue establecer la posible relación entre diagnóstico clínico, el estadio de la enfermedad, el sexo y los fenómenos discursivos estudiados. La hipótesis del estudio sostiene que hay un peor desempeño en el componente evaluativo de la historia entre personas con diagnóstico de esquizofrenia en comparación con las que padecen psicosis afectiva. Asimismo, en la esquizofrenia las dificultades en la elaboración de narraciones constituyen un marcador sensible por manifestarse desde el primer episodio. Para tales propósitos se analizaron 75 entrevistas de sujetos chilenos con los siguientes diagnósticos: 25 personas con esquizofrenia crónica, 25 de primer episodio de esquizofrenia y 25 con psicosis afectiva, constituyendo una muestra representativa de ambas patologías.

\section{MARCo CONCEPTUAL}

\subsection{La esquizofrenia y las psicosis afectivas}

Como es sabido por todos, en la esquizofrenia es necesario tomar en cuenta la ausencia de biomarcadores, por ello, el diagnóstico se basa fundamentalmente en la historia del desarrollo de los síntomas, la entrevista 
clínica y la observación de las conductas de la persona afectada. Se utiliza como marco de referencia los criterios del DSM y el CIE-10, en los que se configura un conglomerado de síntomas que a contar de un período de tiempo provocan deterioro en las condiciones vitales y de adaptación al entorno. Su alta morbi-mortalidad, multidimensionalidad etiológica y curso deteriorante la transforman en un desafío constante para la salud pública y en un permanente reto para la psiquiatría (Crow, 1980; Castilla del Pino, 1991; Andreasen, et al., 1995; Mackenna y Oh, 2005). La nosología de la enfermedad la tipifica como asistemática y heterogénea y esta notoria realidad clínica se ha consignado con rigor en la literatura. En el medio hispánico, Jimeno Bulnes (2002) puntualiza la inclusión de factores probatorios combinados como un requisito forzoso para su diagnóstico (la negrita es nuestra):

El estudio de las manifestaciones de la esquizofrenia puede ligarse directamente al concepto y diagnóstico de la misma, de tal forma que según los criterios diagnósticos empleados (sean de Kraepelin, o Bleuler, o del grupo de San Luis, o los criterios RDC, o las sucesivas versiones de la CIE o DSM), tal o cual síntoma tendrá un mayor o menor peso específico. En todo caso, en lo que la mayoría de -por no decir todos- los autores coinciden es en la heterogeneidad de la enfermedad, que puede expresarse por manifestaciones en las más diversas funciones psicopatológicas. O, dicho con otras palabras, la amplia gama de posibles síntomas de la esquizofrenia supone un estudio en profundidad de la psicopatología misma (Jimeno Bulnes, 2002: 316).

$\mathrm{Al}$ situarse en etapas precoces del ciclo vital, se asocia no solo a un deterioro neurocognitivo y psicosocial significativo, igualmente, de no contar con un tratamiento oportuno y eficaz, tenderá a la cronicidad. Representa un alto costo para el sistema de salud, el sujeto, su familia y sus cuidadores y no existe hasta ahora un tratamiento que logre la remisión de la enfermedad; del mismo modo, sus manifestaciones siempre "implican una serie de disfunciones cognitivas, conductuales y emocionales, no hay un solo síntoma que sea patognomónico de la enfermedad" (DSM-V, 2014: 100).

$\mathrm{Al}$ mismo tiempo, a pesar de que la impronta evolutiva depende en forma aleatoria de la adherencia a los tratamientos psicofarmacológicos, terapéuticos y a los componentes genéticos predisponentes, el factor más significativo en la evolución de la enfermedad es la precocidad del diagnóstico. Una mayor duración de la psicosis no tratada (DUP) ${ }^{1}$ se relacionaría con un inicio insidioso de la enfermedad, una propensión a rehospitalizaciones y una menor respuesta a los fármacos. Las investigaciones demuestran que la reducción del período entre el inicio de los síntomas psicóticos y el co-

${ }^{1}$ DUP: Duration of Untreatment Psicosis (McGorry et al., 2008). 
mienzo del tratamiento evitaría mayores daños neurobiológicos y neurocognitivos, moderando una evolución deteriorante (McGorry et al., 2003). Otros factores responsables de la evolución del cuadro son el sexo y la edad de inicio de la enfermedad. En forma reciente se ha descubierto la incidencia de ambos factores sobre las características clínicas de pacientes del espectro esquizofrénico, y se ha confirmado que entre los hombres habría un inicio más temprano y de mayor deterioro en el curso de la enfermedad (Usdall, 2003; Sánchez et al., 2012). Recalcamos que para una comprensión integrada de esta afección, es imprescindible generar una interfaz explicativa de conocimiento entre diferentes disciplinas. Juzgamos significativo el hecho de que el ámbito de lo social sea el dominio más afectado en estas personas y, por consiguiente, el de las competencias intersubjetivas. Las capacidades funcionales de la comunicación y la interacción en un entorno determinado son actividades sociales que adquieren ribetes casi inabordables para quienes sufren de patologías psiquiátricas.

La psicosis afectiva se ha descrito como una enfermedad mental endógena caracterizada por frecuentes y recurrentes fases afectivas que exteriorizan diversos grados de profundidad de ciclotimia, distimia, manía o estados delirantes. En ella se incluyen formas clínicas del tipo trastorno bipolar, trastornos de ansiedad y depresión mayor, entre otras. En esta patología, a diferencia de la esquizofrenia, no se revela una alteración de la conciencia y a menudo se mantiene el juicio de realidad, es habitual que el sujeto afectado pueda retener sus experiencias de realidad sin interferencias psicóticas. En general se mantienen orientados temporo-espacialmente; sin embargo, presentan rigidez en la modulación afectiva y los tipos de delirios que se registran en la psicosis afectiva tienen relación con los afectos (Marconi, 1970). Las pesquisas de esta patología se filtran a través de los criterios descritos en el CIE-10 y en el DSM pero, al igual que en la esquizofrenia, tampoco se cuenta con marcadores biológicos para su detección; el estudio de la psicosis afectiva ha entrañado profundos cambios paradigmáticos como lo señalan Luque y Berríos:

Por una serie de razones históricas e ideológicas, la semiología de la afectividad no alcanzó el mismo desarrollo que las funciones intelectuales. A lo largo del siglo, las nociones predecimonónicas de manía y melancolía se transformaron en los nuevos conceptos de manía y depresión, y cómo se mezclaron en los estados combinados (locura circular, periódica, doble forma). Este proceso culminó con la integración de todos los estados afectivos en la locura maníaco-depresiva de Kraepelin. Finalmente, esta amplia enfermedad se fue fragmentando por los trabajos, entre otros, de Wernicke, Kleist, Leonhard, hasta culminar en la propuesta de Angst y Perris de separar la depresión unipolar del trastorno bipolar, aceptada desde 1980 por el DSM-III (2011: 143). 
Si bien en la historia de la psiquiatría moderna las formas de detección y clasificación de la psicosis afectiva se han relacionado con el modelo de observación aplicado, existen importantes coincidencias a la hora de describir su perfil nosológico como independiente de las psicosis esquizofrénicas.

\subsection{La narración en la clínica psiquiátrica}

La interacción médico-paciente, en sí misma, constituye un imbricado procesamiento comunicativo que constituye un marco ideal para las pesquisas de algunas dificultades funcionales, junto con la identificación de posibles alteraciones de la cognición presentes en la esquizofrenia y en otras enfermedades mentales (Chaika, 1978; Chapman, 1987; Laguna y Turull, 2000; Belinchón, 2003; Vargas, 2003; Kuperberg, 2010; Salavera y Puyuelo, 2010; Fernández Pérez, 2014). La entrevista clínica en salud mental está basada en el vínculo con el paciente y en la exploración de su conducta a través de la semiología psiquiátrica. Como interacción plantea una gran ventaja informativa y así lo señalaron Labov y Fanshel (1977) en Therapeutic discourse: Psychotherapy as conversation. En este trabajo los autores propusieron un análisis exhaustivo del discurso médico-paciente, que incluye tres pasos esenciales:

i) el análisis del contexto comunicativo global;

ii) la identificación de reglas del discurso y el análisis de las interacciones; $y$

iii) las condiciones indispensables para una comprensión estratégica del funcionamiento cognitivo-comunicativo del afectado.

Ahora bien, la narración es la actividad principal que se realiza en la clínica psiquiátrica. Como señala Lewis, "Psychiatrists listen to stories more than anything else they 'do' and most medical cases are usually summarized as 'stories"' (2011: vii). El psiquiatra estadounidense plantea, en su trabajo The Art of Narrative Psychiatry: Stories of Strength and Meaning, que el arte de escuchar y decodificar historias debe vincularse con el trabajo clínico y teórico en psiquiatría. Asimismo, desde un punto de vista antropológico, cultural y humano, justifica la narración como un recurso que permite mucho más que comunicar eventos personales, "the stories people tell about themselves not only describe their lives but also shapes their lives" (Lewis, 2011: 66). El valor de este recurso ya había sido descrito brillantemente por Jerome Bruner (2003), cuyas consideraciones sobre la narrativa lo sitúan como un mecanismo racional que proporciona marcos y esquemas de conocimientos necesarios para la elaboración de explicaciones del 
mundo, de la realidad y de la experiencia personal, lo que en buenas cuentas constituye el entramado de la propia identidad sometido permanentemente a la negociación del significado:

La creación de un Yo es un arte narrativo [...] La anomalía de la creación del Yo reside en su arribo tanto del interior como del exterior. Su lado interior, [...] lo constituyen la memoria, los sentimientos, las ideas, las creencias, la subjetividad. Parte de su interioridad casi seguro es innata y originariamente específica de nuestra especie [...] Pero gran parte de la creación del Yo se basa también en fuentes externas: sobre la aparente estima de los demás y las innumerables expectativas que derivamos $[\ldots]$ a partir de la cultura en que estamos inmersos (Bruner, 2003: 94).

Bruner (2003) señala que el discurso narrativo no debe reducirse únicamente a la estructura de la trama, ni del dramatismo o reportabilidad del relato. Ya que funciona como el testimonio de sucesos denotados en tener y retener y, citando a Bartlet (1932), señala que cuando recordamos un suceso se nos viene a la memoria un afecto o una actitud sobre lo que recordamos como emocionante, desagradable o vergonzoso. Por ello, la función retórica es sin duda de mayor relevancia que su estructura canónica. Bruner (2000) propone entonces una docena de universales narrativos imbricados en la comprensión y producción de los relatos que traslucen la identidad del narrador:

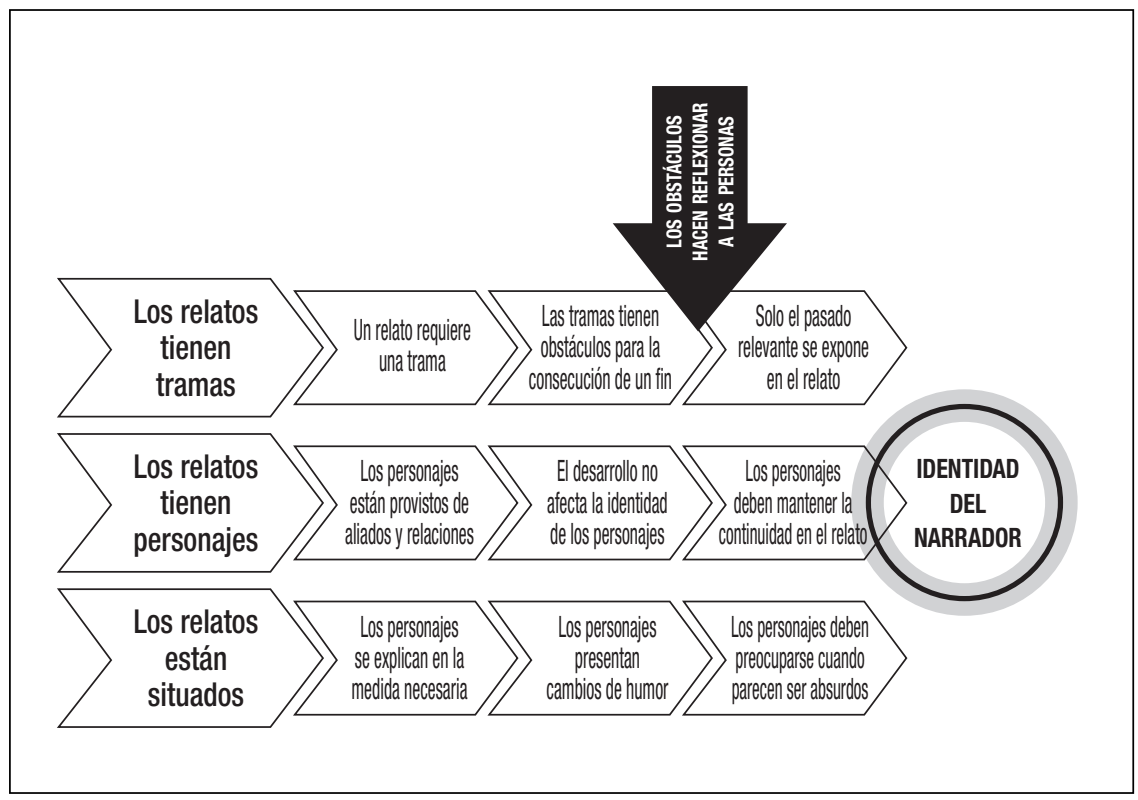


Sobre estos universales narrativos mencionados por Bruner también encontramos sus correspondientes anclajes teóricos en la lingüística. Nos referimos al modelo propuesto en 1967 por Labov y Walestky que vertebra en muchos aspectos el estudio de las narraciones en distintos contextos comunicativos y que, sin duda, sentó bases trascendentales para el estudio empírico de la narración, como lo plantean en Narrative Analysis: Oral Versions of Personal Experience, en donde pormenorizan la organización de las narraciones mediante una superestructura canónica conformada por categorías jerárquicamente organizadas, aunque no forzosamente obligatorias: resumen, orientación, complicación de la acción, evaluación, resolución y coda. Definieron la narración como "as one method of recapitulating past experience by matching a verbal of clauses to the sequence of events which actually occurred" (Labov y Walestky, 1967: 20) y existe amplio consenso sobre el significativo avance en el estudio sistemático de este recurso discursivo gracias a este aporte teórico. En estudios posteriores, Labov (1972, 1985, 1997) ampliará su propuesta y considerará de máxima importancia el componente evaluativo. La evaluación en el relato corresponde a la parte en que se expresa el sentido o propósito de la historia, se mantiene el interés del interlocutor o auditorio, además de ser el porqué de la narración y de servir para mostrar un punto de vista personal. Puede aparecer en diferentes puntos de la historia y las formas de evaluación se manifiestan como procedimientos sintácticos determinados; intensificadores, comparadores, correlativos y explicativos.

No obstante, la notabilidad que ostenta este modelo para efectos de este estudio es preciso considerar algunas características de las narraciones en la clínica psiquiátrica. En primer lugar, las narraciones emergen fruto de un estímulo propuesto por el entrevistador que actúa como un pie de entrada forzado a un evento biográfico muy recurrido debido a la relevancia que tiene para el narrador, esto es, el cómo se inicia o se sobrelleva el proceso mórbido. Este objetivo comunicativo central relega a planos secundarios el posible planteamiento de otros aspectos narrativos supeditados a los requerimientos médicos en pro de la obtención de información clínica clave. Si bien las particularidades como estas pueden ser objetadas por trabar el encuadre narrativo del informante (Schegloff, 1997), subrayamos que no por ello son producciones menos narrativas que los relatos canónicos descritos por Labov y Walestky. Segundo, añadimos el hecho de que en este contexto discursivo las narraciones se ajustan a fines comunicativos como explicar o argumentar. En tercer lugar, consideramos que en la entrevista clínica priman las intenciones subjetivas, axioma que recogemos de las ideas de Camargo (2003) y de Bruner (2006) acerca de la naturaleza situada y contextualizada de los relatos y su evidente arraigo sociocultural como la intención de negociar una autoimagen positiva (Brown 
y Levinson, 1987). La negociación de nuestras características personales para obtener esta imagen positiva es parte de nuestra conducta comunicativa regular que contribuye a la configuración de nuestra identidad, como lo explicita Georgakopoulou, y que en la clínica psiquiátrica adopta ribetes de suma trascendencia, pues se relaciona con el interés en conseguir una aprobación médica sobre la propia autonomía:

Furthermore, aspects of self [...] are co-articulated by interlocutors: negotiated, contested and jointly drafted, simultaneously and to varying degrees of relevance and consequentiality. Last but not least, tellers also construct others. To date, this has mainly been explored through an emphasis on the presentation of characters, voices, for instance through constructed dialogue $[\ldots]$ The aim here has been to explore how importing others' speech and thoughts in the telling of a story fits with aspects of the teller's self; in this respect, 'constructed dialogue' has been frequently studied as a strategy for breaking down, difussing and laminating different aspects of self for interactional and identity work $[\ldots]$. There is certainly analytical resonance in that line of inquiry and we did indeed see $[\ldots]$ how invoking other people's voices may provide further evidence for a teller's view (2007: 117).

Goffman (1983), que aborda este concepto de negociación de la imagen personal o face, sostiene que el sistema que articula las relaciones cara a cara está basado en reglas, normas y convenciones de cuya aceptación depende la cooperación eficaz entre los hablantes. Entonces, entendemos la narración como un pilar central en la construcción y desarrollo de la identidad personal y, en este sentido, el individuo sería consciente de su evolución biográfica e histórica y del lugar que ocupa en un medio social determinado a través de la comprensión de esta perspectiva histórica. Según Labov (1985), las evaluaciones en el relato suponen una plena coincidencia con esta perspectiva histórico-biográfica; por lo mismo, son una conspicua interpretación del proceso mórbido en la psicosis, razón por la que centramos nuestro interés en este componente de su modelo.

Tanto en la esquizofrenia como en la psicosis afectiva, las narraciones se encuentran enmarcadas en tareas introspectivas específicas; por lo tanto, el componente evaluativo está condicionado por las dificultades de los pacientes para expresar una noción tranquilizadora de su propia experiencia (Hernández Monsalve, 2014). Entenderemos las narraciones en Lingüística Clínica como procesos discursivos centrados en la elaboración de interpretaciones sobre la enfermedad y su impacto, asimismo como un mecanismo mediante el que se accede o se da cuenta de la propia identidad. Una condición irrecusable para la rehabilitación es conservar el sentido de si mismo, de un yo que, aunque en conflicto, se encuentre presente, evidencia contenida en la tercera regla de Bruner: la reflexión sobre 
el obstáculo. Esta tarea introspectiva es crucial para comprender el proceso mórbido y asumirlo desde una experiencia analítica y reflexiva, dimensión que abordamos en este trabajo.

\subsection{La evaluación en narraciones de personas con esquizofrenia afectiva}

\subsubsection{Matriz analítica}

En este estudio hemos considerado el uso de mecanismos de evaluación del relato ajustados a la tarea de la identificación de la problemática central como catalizador de la situación personal en salud mental. Esto significa que para este estudio hemos ponderado el desempeño y manejo del componente evaluativo. De este modo, asignamos puntajes a la tipología evaluativa como sigue en la tabla 1:

TABLA 1. Valoración de niveles de desempeño en la evaluación

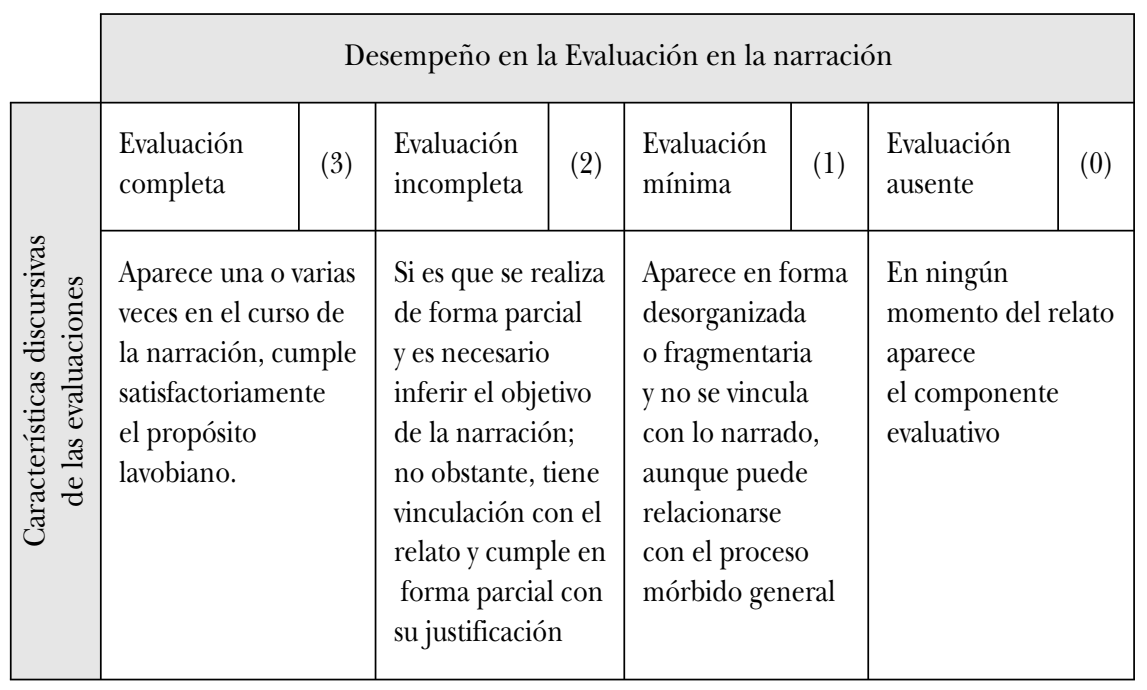

En cuanto al manejo del componente evaluativo, hemos analizado la utilización de estructuras evaluativas descritas por Labov que funcionan como intensificadores, comparadores, correlativos y explicativos en los grupos de pacientes con el propósito de comparar ambas patologías y estadios de desarrollo de la enfermedad. 


\section{Metodología}

\subsection{Participantes}

Para este estudio se analizó una muestra de 75 entrevistas del corpus LEnguaje, PSicosis e Intersubjetividad (LEPSI), de la Unidad de Psicolingüística Clínica de Psiquiatría Sur de la Universidad de Chile. Está constituido por entrevistas clínicas grabadas y transcritas, realizadas a personas con variados diagnósticos psiquiátricos, en los que predomina la esquizofrenia con un $70 \%$. Para este estudio se seleccionaron 25 entrevistas realizadas a personas con esquizofrenia crónica $\left(\right.$ G1-CRE $\left.{ }^{2}\right), 25$ de primer episodio (G2$\mathrm{PEE}^{3}$ ) y 25 entrevistas a personas con diagnóstico de psicosis afectiva (G3-PPA ${ }^{4}$ y G4-CPA ${ }^{5}$ ). Para el grupo de primer episodio de esquizofrenia se consideraron personas con diagnóstico de menos de tres años al momento de la entrevista. Para el grupo de esquizofrenia crónica se consideraron personas que habían sido diagnosticadas hace más de tres años. El rango de edad de PEE es de entre 14 y 24 años y el de CRE entre 25 y 50 años.

Para los controles, se incluyeron 25 entrevistas clínicas realizadas a personas con diagnóstico de psicosis afectiva del corpus LEPSI, pareadas por edad, sexo y características sociodemográficas con el resto de los participantes, del siguiente modo: 12 entrevistas de primer episodio de psicosis afectiva $\left(\mathrm{G} 3-\mathrm{PPA}^{6}\right)$ y 13 entrevistas que corresponden a psicosis afectiva en etapa de cronicidad (G4-CPA $\left.{ }^{7}\right)$.

El diagnóstico de todos los pacientes incluidos en este corpus y en este estudio fue confirmado por un equipo de psiquiatras, quienes utilizaron la estructura de la entrevista clínica para el DSM-IV (SCID-P, 1997a, b) y la escala de síntomas positivos y negativos PANSS para esquizofrenia (Kay et $a l .$, 1987) Todos los pacientes incluidos en este estudio estaban estabilizados psicopatológicamente, recibiendo dosis orales o de depósito de antipsicóticos por espacio mínimo de un mes. En el caso de los PEE, además estaban insertos en el programa $\mathrm{AUGE}^{8}$. La participación para este estudio contó con un consentimiento informado escrito firmado por los pacientes y un familiar o cuidador responsable, además de la aprobación del

${ }^{2}$ G1-CRE: Grupo 1-crónico de esquizofrenia.

${ }^{3}$ G2-PEE: Grupo 2-Primer episodio de esquizofrenia.

${ }^{4}$ G3-PPA: Grupo 3-Psicosis afectiva primer episodio.

${ }^{5}$ G4-CPA: Grupo 4-Psicosis afectiva crónica.

${ }^{6}$ G3-PPA: Grupo 3-Psicosis afectiva primer episodio.

7 G4-CPA: Grupo 4-Psicosis afectiva crónica.

${ }^{8}$ AUGE: Acceso Universal a Garantías en Salud es un programa para la cobertura garantizada por ley de 80 enfermedades para personas afiliadas a los sistemas de salud público o privados de Chile <www.supersalud.gob.cl $>$. 
Comité de Ética Científica (C.E.C.) del Servicio de Salud Metropolitano Sur (S.S.M.S.) de Santiago de Chile. En la tabla 2 reseñamos las características de todos los participantes:

TABLA 2. Datos clínico-demográficos de los participantes

\begin{tabular}{|c|c|c|c|c|c|c|c|}
\hline \multicolumn{4}{|c|}{ GRUPOS } & G1 (G1-CRE) & G2 (G2-PEE) & G3 (G3-PPA) & G4 (G4-CPA) \\
\hline \multicolumn{4}{|c|}{ DIAGNÓSTICO } & \multicolumn{2}{|c|}{ ESQUIZOFRENIA } & \multicolumn{2}{|c|}{ PSICOSIS AFECTIVA } \\
\hline \multicolumn{4}{|c|}{$\begin{array}{l}\text { ESTADIO } \\
\text { DE LA ENFERMEDAD }\end{array}$} & Crónico & $\begin{array}{l}\text { Primer } \\
\text { episodio }\end{array}$ & $\begin{array}{l}\text { Primer } \\
\text { episodio }\end{array}$ & Crónico \\
\hline \multicolumn{4}{|c|}{$\mathrm{N}=75$} & $\mathrm{n}=25$ & $\mathrm{n}=25$ & $\mathrm{n}=12$ & $\mathrm{n}=13$ \\
\hline \multirow{3}{*}{ 空 } & \multicolumn{3}{|l|}{ MED } & 35 & 18,9 & 16,1 & 33 \\
\hline & \multicolumn{3}{|l|}{ MIN } & 25 & 14 & 14 & 26 \\
\hline & \multicolumn{3}{|l|}{ MAX } & 50 & 22 & 20 & 41 \\
\hline \multirow{2}{*}{ 离 } & \multicolumn{3}{|c|}{ MUJERES } & 12 & 11 & 6 & 5 \\
\hline & \multicolumn{3}{|c|}{ HOMBRE } & 13 & 14 & 6 & 8 \\
\hline \multirow{2}{*}{\multicolumn{3}{|c|}{ AÑOS DE ESCOLARIZACIÓN }} & 8 & (25) $100 \%$ & (25) $100 \%$ & (12) $100 \%$ & (13) $100 \%$ \\
\hline & & & 12 & (15) $60 \%$ & (3) $12 \%$ & (8) $66,6 \%$ & (10) $77 \%$ \\
\hline \multirow{4}{*}{\multicolumn{2}{|c|}{ OCUPACIÓN }} & \multicolumn{2}{|l|}{ Con empleo } & (3) $12 \%$ & (5) $20 \%$ & (4) $33 \%$ & (2) $15,3 \%$ \\
\hline & & \multicolumn{2}{|c|}{ Desempleado } & (12) $48 \%$ & (12) $48 \%$ & (6) $50 \%$ & (6) $46,1 \%$ \\
\hline & & \multicolumn{2}{|c|}{ Dueña de casa } & (10) $40 \%$ & (0) $0 \%$ & (0) $0 \%$ & (1) $7,9 \%$ \\
\hline & & \multicolumn{2}{|l|}{ Estudiante } & (0) $0 \%$ & (8) $32 \%$ & (2) $16,6 \%$ & (4) $30 \%$ \\
\hline
\end{tabular}

\subsection{Procedimiento}

\subsubsection{Esquema operativo}

El esquema operativo del presente estudio comprendió una selección aleatoria de las entrevistas clínicas del corpus LEPSI. Luego se identificaron y analizaron las narraciones desplegadas en ellas para verificar cuáles eran las características particulares del componente evaluativo. Posteriormente, se compararon los desempeños de los cuatro grupos de participantes para establecer las diferencias entre ellos y analizar el nivel de desempeño alcanzado. En lo que sigue se realizó el procesamiento estadístico descriptivo de los datos y la interpretación de los resultados. 
El diseño de este estudio es transversal, comparativo y no experimental. En lo que se refiere a la descripción del procedimiento estadístico utilizado, se realizó un análisis discursivo de las entrevistas transcritas, a partir del cual se generaron variables que fueron categorizadas para la valoración del desempeño en la evaluación del relato. De esta forma, al tratarse de un estudio con variables cuantitativas múltiples, comprobamos la distribución normal de los datos conseguidos y utilizamos una prueba no paramétrica: chi cuadrado, que sirvió para correlacionar la presencia o ausencia de algunas variables con factores como el diagnóstico, el estadio de la enfermedad y el sexo de los participantes. En todos los casos, el grado de significación estadística se definió en $\mathrm{p}=<0,05$.

\section{Presentación y ANÁlisis de los RESUltados}

\subsection{Consideraciones previas}

Con el fin de diferenciar las evaluaciones del relato y el desempeño en este aspecto de la narración entre los grupos de personas con esquizofrenia y psicosis afectiva, los datos obtenidos están organizados en dos niveles de observación que pueden aportar evidencia convergente:

i) en términos descriptivos, según frecuencias absolutas y porcentajes de frecuencia de las variables diagnóstico, estadio de la enfermedad y sexo; y

ii) en términos cualitativos, en relación con la eficacia comunicativa lograda por los participantes del estudio en dichas variables.

\subsection{Indicadores y variables significativas}

En esta sección se exponen, en primer lugar, los resultados del estudio en cuanto a la relación entre el desempeño comunicativo en este aspecto de las narraciones y las tres variables extralingüísticas consideradas en el análisis: diagnóstico, estadio de la enfermedad y sexo de los sujetos de la muestra. En lo que sigue, se expondrán fragmentos para comparar el empleo de los mecanismos de evaluación que se registraron en los grupos estudiados.

\subsubsection{Desempeño y diagnóstico}

En relación con las diferencias observadas en el desempeño de la evaluación registrado en el relato en ambas patologías estudiadas, puede observarse que este aspecto se encuentra significativamente empobrecido 
en los grupos de esquizofrenia en contraste con los grupos de psicosis afectiva. De acuerdo con los datos suministrados en la tabla 3 y en el gráfico 1, la evaluación ausente se registró solamente entre los grupos de esquizofrenia, con un 14,66\% de las ocurrencias. Asimismo, la evaluación mínima alcanza notables diferencias entre ambas patologías y en la esquizofrenia puede verificarse un peor rendimiento en el desarrollo de la evaluación en el relato, en contraste con la psicosis afectiva, un $22,66 \%$ y un $2,6 \%$ respectivamente. En el caso de la evaluación incompleta, también podemos apreciar una diferencia reveladora entre las patologías, ya que en esquizo-

TABla 3. Frecuencia en el desempeño de la evaluación en narración y diagnóstico

\begin{tabular}{|l|c|c|c|c|}
\cline { 2 - 5 } \multicolumn{1}{c|}{} & \multicolumn{4}{c|}{ DESEMPEÑO EN LA EVALUACIÓN EN LA NARRACIÓN } \\
\hline DIAGNÓSTICO & $\begin{array}{c}\text { EVALUACIÓN } \\
\text { AUSENTE }\end{array}$ & $\begin{array}{c}\text { EVALUACIÓN } \\
\text { MÍNIMA }\end{array}$ & $\begin{array}{c}\text { EVALUACIÓN } \\
\text { INCOMPLETA }\end{array}$ & $\begin{array}{c}\text { EVALUACIÓN } \\
\text { COMPLETA }\end{array}$ \\
\hline ESQUIZOFRENIA & $14,66 \%$ & $22,66 \%$ & $24 \%$ & $5,33 \%$ \\
\hline $\begin{array}{l}\text { PSICOSIS } \\
\text { AFECTIVA }\end{array}$ & $0,0 \%$ & $2,66 \%$ & $14,60 \%$ & $16 \%$ \\
\hline
\end{tabular}

GRÁFICO 1. Desempeño de la evaluación y diagnóstico

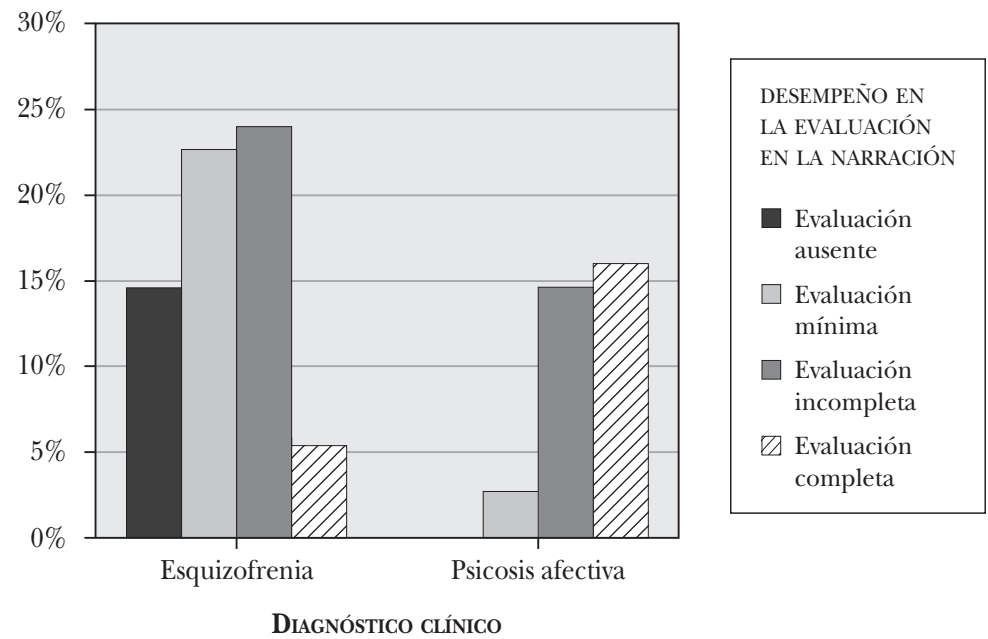


frenia alcanza el $24 \%$ de las ocurrencias, en contraste con el $14 \%$ de psicosis afectiva. Por último, en lo que corresponde a la evaluación completa, pudimos verificar que el $16 \%$ de las personas con psicosis afectiva logra elaborarla, en contraste con apenas el 5,3\% en la esquizofrenia. A pesar de que la flexibilidad narrativa puede ser compleja y variable, resulta fehaciente que entre los grupos de psicosis afectiva se bosquejan evaluaciones centradas en la propia vivencia de los hechos, cuyos resultados son productos narrativos definidos sobre el qué y el porqué se sienten de tal o cual forma. Por el contrario, en los grupos de esquizofrenia los productos narrativos no se vinculan explícitamente a si mismos, la ejecución a veces descansa sobre los hechos desnudos, sin interpretación o relación con ellos como protagonistas de un proceso mórbido. Los datos que arroja el cruce de estas variables resultaron significativos estadísticamente; el valor de chi cuadrado es de $22,723^{\mathrm{a}}(\mathrm{p}<0,00)$.

A continuación la transcripción de dos ejemplos de nuestros hallazgos:

\begin{tabular}{|c|c|c|c|}
\hline & $\begin{array}{l}\text { EVALUACIÓN COMPLETA } \\
\text { EN PSICOSIS AFECTIVA }\end{array}$ & $\begin{array}{l}\text { EVALUACIÓN AUSENTE } \\
\text { EN ESQUIZOFRENIA }\end{array}$ & \\
\hline 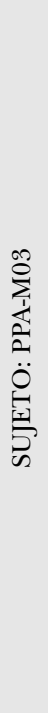 & $\begin{array}{l}\text { 005. E: ¿altos y bajos?// ¿cómo es eso? } \\
\text { 006. S: de repente puedo estar muy bien/ } \\
\text { muy piola/[piola=estar muy callado, sin lla- } \\
\text { mar la atención] muy normal y después es } \\
\text { como que estoy mal/ decaída/ ¿cachai? } \\
\text { [cachai=entiendes] } \\
\text { 007. E: y eso se ha mantenido este último tiem- } \\
\text { po// o tú sientes que estás mejor o// } \\
\text { 008. S: peor/ peor } \\
\text { 009. E: ¿por? } \\
\text { 010. S: bueno/ hace poco estuve bien mal } \\
\text { 011. E: ya } \\
\text { 012. S: y mmm<pausa or> / me traté de ma- } \\
\text { tar// y mmm// ya hablé con la Vy// mmm } \\
<\text { pausa or>/ tuvimos una conversa [conver- } \\
\text { sación] y mmm <pausa or>/ahora estoy tra- } \\
\text { tando de estar más estable. } \\
\text { 013. E: y/eso/ ¿te pasó cuándo? } \\
\text { 014. S: hace como tres semanas }\end{array}$ & $\begin{array}{l}\text { 007. E: ¿enfermedad?/ ¿qué en- } \\
\text { fermedad? } \\
\text { 008. S: esquizofrenia/ esquizo- } \\
\text { frenia } \\
\text { 009. E: esquizofrenia/ ya/ } \\
\text { ¿y..<pausa or> usted recuer- } \\
\text { da porque fue hospitalizado } \\
\text { en esta/ en esta oportuni- } \\
\text { dad? / ¿recuerda porque lo } \\
\text { hospitalizaron? } \\
\text { 010. S: me caía de la cama } \\
\text { 011. E: ¿cómo es eso? } \\
\text { 012. S: eeh<pausa or }>\text { mm <5.0> } \\
\text { 013. E: ¿mmm? } \\
\text { 014. S: me caía de la cama } \\
\text { 015. E: se caía de la cama }\end{array}$ & 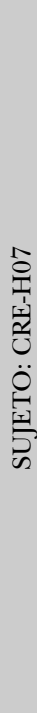 \\
\hline
\end{tabular}

\subsubsection{Desempeño y estadio de la enfermedad}

Los resultados obtenidos para desempeño en la evaluación y estadio de la enfermedad pueden apreciarse en la tabla de frecuencia 4 y en el gráfi- 
co 2. El desempeño de los grupos de primer episodio es sobresaliente en contraste con los grupos de pacientes crónicos. La evaluación ausente no se pesquisa en los grupos de primer episodio; en cambio, en los crónicos alcanza un 14,2\% de las ocurrencias. La evaluación puede considerarse una estructura narrativa conservada entre los pacientes de primer episodio, lo que puede interpretarse como un signo efectivo de la utilización de habilidades intersubjetivas. En cuanto a la evaluación mínima, los grupos de primer episodio registraron un $14,6 \%$ de las ocurrencias y los grupos

TABLA 4. Frecuencia en el desempeño de la evaluación en narración y estadio de la enfermedad

\begin{tabular}{|c|c|c|c|c|}
\cline { 2 - 5 } \multicolumn{1}{c|}{} & \multicolumn{4}{c|}{ DESEMPEÑO EN LA EVALUACIÓN EN LA NARRACIÓN } \\
\hline $\begin{array}{c}\text { ESTADIO DE LA } \\
\text { ENFERMEDAD }\end{array}$ & $\begin{array}{c}\text { EVALUACIÓN } \\
\text { AUSENTE }\end{array}$ & $\begin{array}{c}\text { EVALUACIÓN } \\
\text { MÍNIMA }\end{array}$ & $\begin{array}{c}\text { EVALUACIÓN } \\
\text { INCOMPLETA }\end{array}$ & $\begin{array}{c}\text { EVALUACIÓN } \\
\text { COMPLETA }\end{array}$ \\
\hline $\begin{array}{c}\text { PRIMER } \\
\text { EPISODIO }\end{array}$ & $0,00 \%$ & $14,60 \%$ & $21 \%$ & $14 \%$ \\
\hline CRÓNICO & $14,20 \%$ & $12 \%$ & $16 \%$ & $8 \%$ \\
\hline
\end{tabular}

GRÁFICO 2. Desempeño de la evaluación y estadio de la enfermedad

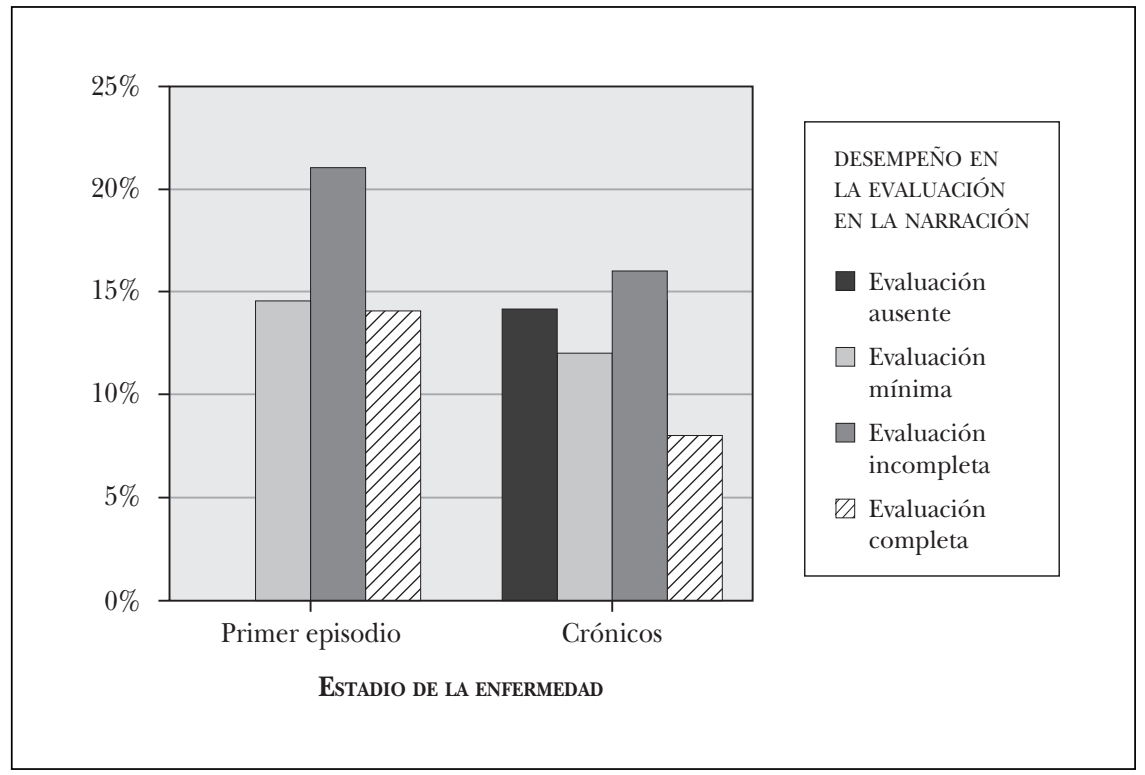


de crónicos un 12\%. Si bien las ocurrencias entre crónicos son menores, tenemos que recordar que a causa del proceso mórbido es en el primer episodio cuando se revelan conductas reticentes y poco colaborativas. En la evaluación incompleta los pacientes elaboraron evaluaciones parciales modeladas con la intervención del entrevistador para comprender de forma explícita lo que esbozaba el narrador. Se presentó un 21\% entre los grupos de primer episodio, en cambio solo un 16\% entre los crónicos; este resultado confirma lo planteado por la literatura en cuanto a la desinhibición discursiva de los pacientes crónicos. Finalmente, la evaluación completa fue pesquisada en el 14\% de las ocurrencias entre los grupos de primer episodio en contraste con un $8 \%$ entre las personas de los grupos de crónicos. La capacidad para evaluar, explicar e interpretar el significado más relevante de lo narrado es una habilidad crucial para una competencia funcional del discurso. Los resultados fueron significativos estadísticamente, el valor de chi cuadrado es de $12,773^{\mathrm{a}}$ ( $\left.\mathrm{p}<0,05\right)$. A continuación, dos ejemplos de nuestros hallazgos:

\begin{tabular}{|c|c|}
\hline PEE-H01 & CRE-H07 \\
\hline $\begin{array}{l}\text { 013. S: que siento que las personas mmeem<pausa } \\
\text { or> me siento como muy importante/ ese es el } \\
\text { porte/ delirio de importancia/ no sé } \\
\text { 014. E: yaaa<pausa or> } \\
\text { 015. S: ese es/ es más lo básico/ yo he leído mucho } \\
\text { esto de la esquizofrenia/ que las personas es- } \\
\text { quizofrénicas tienen muy/ se dan mucha im- } \\
\text { portancia/ o sea/ssee <pausa or ssee <pausa } \\
\text { or> se sienten muy únicas/ muy importantes/ y } \\
\text { se sienten muy solas también/ y eso me pasa/ } \\
\text { entonces yo me digo que/ claro: "esta persona } \\
\text { me está mirando a mí" y con la otra/ y/ le dijo } \\
\text { a la/ a la cajera y/ las dos me miraron" / "y este } \\
\text { es el niño que salió en el internet"/ ahí en toda } \\
\text { la cues <palabra cortada> / ahí mmm/ en las pá- } \\
\text { ginas sociales/ y se me arma un boche [boche= } \\
\text { ruido escandaloso] en la cabeza / ooh <pausa or> } \\
\text { no quería/ no hallaba donde meterme } \\
\text { 016. E: por/ no te entiendo/ si la gente te mira/ } \\
\text { esas dos personas que estaban conversando } \\
\text { ahí/ te miraron/ ¿y qué entiendes tú?/ ¿qué in- } \\
\text { terpretas de esa mirada? } \\
017 \text {. S: es que yo que la note como que se esta- } \\
\text { ba riendo/ entonces yo dije: "se están riendo } \\
\text { de mí" }\end{array}$ & $\begin{array}{l}\text { 001. S: bien/ jah?/ jcierto?/ sí// bue- } \\
\text { no yo me llamo X/ espero que nos } \\
\text { llevemos bien hoy día/ para que } \\
\text { tengamos un día feliz<5.0>/eh } \\
<5.0>\text { /yo quiero decirles mi<5.0>/ } \\
\text { parte de mi vida // es que puedo } \\
\text { darme cuenta de toda la realidad } \\
\text { concreta/ que nos hace mejo- } \\
\text { res// cuando nace un hijo //de } \\
\text { una pareja//innato/ conciencia } \\
\text { innato/ o sea conciencia//y lo } \\
\text { otro/ género humano //de la } \\
\text { parte congenia/ congenia//con- } \\
\text { génito/ ¿cierto? // viene más allá } \\
\text { de innato/ congénito//eh <pausa } \\
\text { or ext / viene del verbo mental } \\
\text { como proceso/ la verdad// va por } \\
\text { hecho/ lo congénito //somos } \\
\text { capaces de discernir el bien del } \\
\text { mal/ para después tener concien- } \\
\text { cia de saber una//una esencia } \\
\text { del bien//lo //para manejar //el } \\
\text { comportarse con influencias defi- } \\
\text { nitivas del mundo [...] }\end{array}$ \\
\hline
\end{tabular}




\subsubsection{Desempeño y sexo}

En la comparación del desempeño en la evaluación entre hombres y mujeres no encontramos resultados significativos estadísticamente. El valor de chi cuadrado fue de, $679^{\mathrm{a}}(\mathrm{p}<0,878)$. La literatura sobre psicosis ha señalado que en cuanto a sexo no se distinguen rasgos diferenciadores significativos en la etapa de cronicidad; sin embargo, hay acuerdo en que, en el primer episodio, los llamados síntomas negativos se dan con mayor pre-

TABLA 5. Frecuencia en el desempeño de la evaluación en narración y sexo

\begin{tabular}{|c|c|c|c|c|}
\cline { 2 - 5 } \multicolumn{1}{c|}{} & \multicolumn{4}{c|}{ DESEMPEÑO EN LA EVALUACIÓN EN LA NARRACIÓN } \\
\hline SEXO & $\begin{array}{c}\text { EVALUACIÓN } \\
\text { AUSENTE }\end{array}$ & $\begin{array}{c}\text { EVALUACIÓN } \\
\text { MÍNIMA }\end{array}$ & $\begin{array}{c}\text { EVALUACIÓN } \\
\text { INCOMPLETA }\end{array}$ & $\begin{array}{c}\text { EVALUACIÓN } \\
\text { COMPLETA }\end{array}$ \\
\hline MUJERES & $5,3 \%$ & $10,6 \%$ & $18,66 \%$ & $10,6 \%$ \\
\hline HOMBRES & $9,33 \%$ & $14,66 \%$ & $20 \%$ & $10,6 \%$ \\
\hline
\end{tabular}

Gráfico 3. Desempeño de la evaluación y sexo

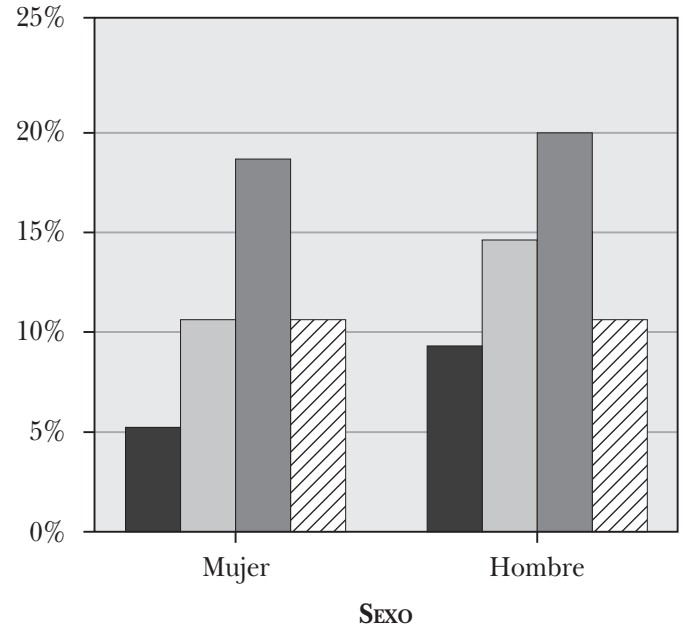

DESEMPEÑO EN

LA EVALUACIÓN

EN LA NARRACIÓN

Evaluación ausente

$\square$ Evaluación mínima

Evaluación incompleta

$\square$ Evaluación completa

SEXo 
eminencia en hombres (Riecher-Rossler y Hafner, 2000), lo que de algún modo explicaría la mayor reticencia a elaborar narraciones completas en hombres con psicosis de primer brote. En un estudio de Baeza et al. (2010) se explica que las diferencias de género en pacientes con esquizofrenia podrían relacionarse con la edad de inicio, el consumo de sustancias y la neuroimagen estructural. No obstante, aclaran que en población infantojuvenil dichas diferencias podrían pesquisarse únicamente con neuroimagen. Ahora bien, desde el campo de la lingüística y en especial de la Sociolingüística y el Análisis del Discurso se han establecido hallazgos importantes sobre las diferencias de género en las narraciones (Tannen, 1993; Wodack y Benke, 1997; Silva Corvalán, 2001; Prieto y San Martín, 2002-2003; Camargo, 2003 y Moreno Fernández, 2005). Es muy importante señalar que debido al carácter limitado del presente estudio no nos fue posible encontrar las diferencias descritas en los estudios del lenguaje que citamos más arriba. En consecuencia, pensamos que si se sistematizan estudios sobre la relación entre género, discurso y psicosis puede abrirse un interesante flanco de observación de patologías mentales graves. A pesar de que estadísticamente no observamos diferencias de género, podemos afirmar que, en general, los hombres de los cuatro grupos estudiados se desempeñaron de una forma más deficiente que las mujeres, como podemos corroborar en la tabla 5 y en el gráfico 3. A continuación, dos ejemplos de nuestros hallazgos:

\begin{tabular}{|c|c|c|c|}
\hline & $\begin{array}{c}\text { EVALUACIÓN COMPLETA } \\
\text { EN PSICOSIS AFECTIVA-MUJERES }\end{array}$ & $\begin{array}{c}\text { EVALUACIÓN AUSENTE } \\
\text { EN ESQUIZOFRENIA-HOMBRE }\end{array}$ & \\
\hline 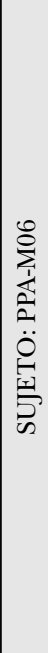 & $\begin{array}{l}\text { 006. S: ahora/ ya que superé la parte más } \\
\text { crítica de mi depresión/ me doy cuenta } \\
\text { que quiero hacer hartas cosas/ quiero } \\
\text { estudiar literatura// me encanta leer/ } \\
\text { escribir/ aunque con este tema de la de- } \\
\text { presión dejé de lado todo eso. } \\
\text { 007. E: ya } \\
\text { 008. S: como que ahora me cuesta con- } \\
\text { centrarme en leer/ no escribo igual que } \\
\text { antes y eso igual me frustra/ Me gusta- } \\
\text { ría trabajar en un café literario porque } \\
\text { no quiero algo// no quiero ser profeso- } \\
\text { ra porque sería muy cuadrado } \\
\text { 009. E: mmm } \\
\text { 010. S: reglas que yo no quiero seguir/ } \\
\text { quiero hacerlo todo a mi pinta } \\
\text { 011. E: yaaa }\end{array}$ & $\begin{array}{l}\text { 051. E: en el 86/ perfecto/ ahí le } \\
\text { diagnosticaron esquizofrenia/ y } \\
\text { qué le pasó el eeel<pausa or> en el } \\
86 \text { que le diagnosticaron esquizo- } \\
\text { frenia/ cuénteme un poquito que } \\
\text { le pasó a usted ese año. } \\
\text { 052. S: tuve un accidente/ tuve un } \\
\text { accidente } \\
\text { 053. E: ¿tuvo un accidente?/ ya/ } \\
\text { ¿cuénteme más de este acciden- } \\
\text { te?// ¿qué/ qué tipo de accidente } \\
\text { tuvo usted? } \\
\text { 054. S: a la cabeza/ a la cabeza/ a la } \\
\text { cabeza } \\
\text { 055. E: ya/ ¿qué pasó con su cabeza? } \\
\text { 060. S: no se }\end{array}$ & 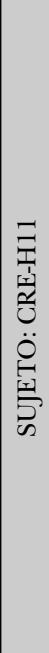 \\
\hline
\end{tabular}




\subsection{Sintaxis evaluativa}

\subsubsection{Intensificadores}

Están presentes en la narración como mecanismos para indicar énfasis (Álvarez, 2008). Para Labov (1985), en esta categoría se encuentran los énfasis prosódicos, los gestos, además de la repetición y del uso de proverbios.

La función de los intensificadores en la narración no difiere mayormente en ambas patologías; no obstante, es de interés mencionar que encontramos construcciones de mayor elaboración gramatical entre las personas del grupo de psicosis afectiva; además se emplearon recursos prosódicos y gestuales como énfasis y gestos con las manos y el cuerpo, como pasamos a ejemplificar:

\begin{tabular}{|c|c|}
\hline [CPA: H05] & \multicolumn{1}{|c|}{ [CRE-M08] } \\
\hline 124. S: quiero/ quiero planificarme & 047. S: me enteré que mis notas [calificaciones] \\
[muy enfático] quiero/ quiero/ estar & fueron bajadas/ en el colegio/ en la universi- \\
acá [indica con las manos indicando & dad/ en la PAA [PAA=Prueba de Aptitud Acadé- \\
hacia el piso en forma enérgica] y re- & mica, para la selección universitaria chilena que se \\
cuperarme por completo [gesticu- & aplicó entre 1966 y 2002, se sustituyó por la Prue- \\
la juntando las manos con la palma & ba de Selección Universitaria PSU]// y durante \\
hacia abajo y separándolas hacia los & muchos años me esmeré/ me esmeré/ me es- \\
lados, se repite el gesto dos veces] & meré/ me esmeré en llegar a la universidad / \\
125. E: ¿tiene proyectos para su fu- & y pasé por geografía/ pero ahora corregí/ que \\
turo? & nunca estuve en la universidad/ mi tarea en \\
126. S: claro [enfático] pasé de/de/ de & la universidad fue otra/ llegué a una carrera \\
doctor/ en doctor/ pasé mala[s] / & donde había mucha gente conflictiva/ des- \\
mala[s] experiencias si/ nunca tuve & pués se ordenó eso/ y en rigor sé que tengo \\
un puro doctor/ pero ahora quie- & un título ad honorem que es de periodista \\
ro/ quiero estabilizarme/ quiero/ & y un master en comunicación estratégica//y \\
ayudar a mi familia/ ayudar a mi & podría mmm <pausa or> tengo no-home// ser \\
familia/ por eso estoy muy conten- & el profesor que quisiera ser// pero me hubie- \\
to/ y...<pausa or>/y trabajar/ por- & se gustado ser <alarg> médico sin fronteras/ \\
que yo/ yo/ yo/ yo he trabajado. & pero para ser médico hay que intervenir/y \\
& eso no lo he hecho yo \\
\hline
\end{tabular}

\subsubsection{Comparadores}

Los comparadores operan elicitando episodios que no se plantean en la narración, de este modo se abre la posibilidad de especular sobre un nuevo escenario narrativo para los eventos relatados y evaluarlos en compa- 
ración con los que en verdad sucedieron. Según Labov (1985), se reconoce a partir de una cláusula narrativa no marcada (+pretérito -negación) y se convierte en una evaluación comparativa al hacerla marcada (-pasado + negación). Este es el caso del presente histórico que corresponde a una evidente forma evaluativa, como lo plantea Álvarez (2008): "la hablante cuenta cómo pasó por el lado del ladrón que le arrancó sus dos cadenas: pero yo de lo más tranquila paso por un lado; y cuál es mi sorpresa que el tipo me metió la mano" (Álvarez, 2008: 214). En las entrevistas que utilizamos para este trabajo este tipo de estructuras fueron más frecuente entre los grupos de psicosis afectiva:

\begin{tabular}{|c|c|}
\hline CAP-M06 & CRE-M08 \\
\hline 056. S: coming/ coming/ ¿tú me quieres & 001. E: ya/ a ver M/ cuéntame/ ¿cómo has \\
preguntar si yo tengo una hipótesis de & estado este último tiempo? \\
todo esto? [se dirige al entrevistador] / & 002. S: ya/ bueno// te cuento lo último/ \\
ya/ está bien/ te la voy a decir/// [se & mmm<pausa or>/ por ejemplo/ ahora/ \\
frota las manos con un gesto infantil]/ Mi & yo tengo pegado el tema de las risas/ no \\
mamá [enfática] Mi mamá va a la iglesia & es que yo me ría con las personas/ <ríe> \\
los domingos/ todos los domingos/ la & / no/ no es así/ es como una risa con \\
iglesia los domingo/ ¿la cachas? & los ojos/ es como que si yo me estuvie- \\
057. E: mmm [arruga entrecejo] & ra burlando/ o poco menos de la per- \\
058. S: ya, mi madre era como la Quin- & sona/ eso es lo que me está pasando \\
trala [La Quintrala=Catalina de los Ríos & ahora/ en mi casa me dicen que no es \\
Lisperguer, aristócrata chilena del sXVI fa- & así/ que son cosas mías/ pero no sé \\
mosa por el trato cruel hacia sus sirvientes, & yooo <pausa or>/ me cuesta creer que \\
fue acusada de múltiples asesinatos y su & eso es así. \\
nombre es sinónimo de maldad]/// [mira & 003. E: ¿qué te cuesta creer? \\
al entrevistador expectante] logramos des- & 004. S: Es que me pregunto/ ¿y si es cier- \\
truirla/ pero ella no quiere irse/ por & to que me río con los ojos?/ ¿la gente \\
su nieta/ porque ella la ama// mira, & se da cuenta de que me burlo?//pero \\
como que le pegaron no sé cuántos & no me burlo. \\
balazos// ya/ ¿eso ya está bien? no po' & \\
[pues] lo soporté/ habría sido bueno & \\
que no fuera así. & \\
\hline
\end{tabular}

\subsubsection{Correlativos}

Son estructuras correlativas que comportan continuidad temporal, como es el caso de los gerundios. Los datos analizados para este trabajo reportaron una escasa recurrencia de este tipo de estructuras. A continuación, dos ejemplos de correlativos: 


\begin{tabular}{|c|c|}
\hline PPA-M01 & CRE-H13 \\
\hline $\begin{array}{l}\text { 110. E: cuándo estuvo bien delgada/ ¿le pro- } \\
\text { ducía algo eso?/ ¿con los } 39 \text { kilos? } \\
\text { 111. S: si me sentía bien/ me sentía bien por } \\
\text { estar bajando/ de peso// pero// no tenía } \\
\text { ganas de levantarme porque/ me estaba } \\
\text { deprimiendo/ entristeciendo/ no sé } \\
\text { 112. E: entonces/ ¿no se sentía bien con ese } \\
\text { peso? } \\
\text { 113. S: yo igual quería seguir bajando/ adel- } \\
\text { gazando/ adelgazando/ mmm <pausa or> }\end{array}$ & $\begin{array}{l}\text { 020. S: [...] he sido en el día a día una } \\
\text { muestra concreta de quién era yo/ } \\
<5.0>\text { más allá de lo que decían que lo } \\
\text { mío era esquizofrenia// lo mío era } \\
\text { una reacción fisiológica a un entorno } \\
\text { hostil al que estaba// de ahí/ siendo } \\
\text { under enfrentándome/ confrontán- } \\
\text { dome/ me fui viendo envuelto en } \\
\text { descrédito/ descalificaciones/ prejui- } \\
\text { cios/ eso [...] }\end{array}$ \\
\hline
\end{tabular}

\subsubsection{Explicativos}

Esta evaluación se elabora con conjunciones causales y frases subordinadas en cláusulas anexas a la cláusula principal (Álvarez, 2008). Su utilización fue recurrente entre los grupos de psicosis afectiva; no obstante, también los registramos entre pacientes de los grupos de esquizofrenia. He aquí dos ejemplos:

\begin{tabular}{|c|c|}
\hline PPA-H04 & CRE-M03 \\
\hline $\begin{array}{l}\text { 027. E: ¿y nos puedes contar de que se trata } \\
\text { eso? / ¿qué te pasó? } \\
\text { 028. S: lo que pasa es que yo estaba inten- } \\
\text { tando entrar a la Armada/ la Armada de } \\
\text { Chile/ y hice la prueba// todo pero me } \\
\text { fue mal// no quedé// entonces intenté } \\
\text { suicidarme y// después de intentarme sui- } \\
\text { cidar empecé a ver cosas/ empecé a ver la } \\
\text { muerte que venía atrás de mí/ y después } \\
\text { me enfermé y//porque empiezo a ver// } \\
\text { tengo alucinaciones y escucho voces. }\end{array}$ & $\begin{array}{l}\text { 039. E: las voces/ ¿en qué le afectan a } \\
\text { usted?/ ¿están fuera o dentro de su } \\
\text { mente? / cuénteme. } \\
\text { 040. S: si también fuera de la mente/ } \\
\text { también fuera de la mente porque } \\
\text { ellos cuando/ conversan entre sí/ no } \\
\text { se escucha o hablan bajo: "a veces no- } \\
\text { sotros queremos enseñarte" " "quere- } \\
\text { mos hacernos amigos tuyos"/ ¡claro! } \\
\text { [irónica] y de qué manera/ ¿cómo va } \\
\text { a ser amigo si/ me hacen todas esas } \\
\text { cosas y yo tengo que soportarlo?/ así } \\
\text { que ando por la casa/ dando vuel- } \\
\text { tas// me pongo para allá/ para acá/ } \\
\text { me siento/ me paro/ yyy<pausa or> y } \\
\text { así // sooon<pausa or > varias voces }\end{array}$ \\
\hline
\end{tabular}




\section{Discusión}

La investigación de los aspectos narrativos de la interacción médicopaciente tiene una fuerte implicación del texto-contexto. La emergencia de los relatos en la clínica psiquiátrica es un marco de pesquisas de suma relevancia para la comprensión de la enfermedad, pero, sobre todo, para acercarnos a la dimensión humana del afectado. Si a esto le sumamos la inexistencia de marcadores neurobiológicos en patologías graves como la esquizofrenia, el lenguaje y su estudio sistemático se convierten en una vía crucial de aproximación al funcionamiento cognitivo y psicosocial de los afectados. A este respecto, es indudable que la narración de una experiencia personal y, en suma, el ejercicio de delinear una imagen personal consistente conlleva mayores dificultades para las personas con esquizofrenia en comparación con aquellas que padecen psicosis afectiva. En los primeros, se advierten fallos desde el primer episodio, no solo en el manejo de recursos lingüísticos, sino sobre todo en las funciones intersubjetivas y de vinculación social. Conjeturamos, por tanto, que las anomalías en el discurso narrativo pueden ser un indicador de déficit comunicativo primario para esquizofrenia (Figueroa, 2015).

\section{Conclusiones}

Es posible sintetizar nuestros hallazgos como sigue:

a) Existen diferencias relevantes en el desempeño de la evaluación en la narración entre ambas patologías.

b) La variable diagnóstico de la enfermedad evidenció contrastes categóricos tanto en la producción narrativa, como en el componente evaluativo. Los grupos de esquizofrenia operaron en general con un peor desempeño en la evaluación y una restringida variedad de mecanismos sintácticos para evaluar los relatos. Esto sugiere que el desarrollo de esta tarea discursiva es un indicador informativo a tomar en cuenta como evaluación del funcionamiento cognitivo de personas con psicosis. En cuanto a los grupos diagnosticados con psicosis afectiva, pudimos corroborar la presencia de marcas discursivas como la utilización constante, reiterativa y fluida de la primera persona, la progresión temporal, la adecuación contextual del escenario narrativo, la asignación de roles a los personajes y, por ende, de la evaluación de sus acciones o las propias mediante el empleo de expresiones calificativas, repeticiones y, especialmente, de la conservación de una macroestructura narrativa (inicio, nudo, desenlace). 
c) La variable estadio de la enfermedad reflejó una deficiente ejecución de las narraciones en general entre las personas del grupo crónico de esquizofrenia y, específicamente, en los mecanismos de evaluación del relato. En el caso del grupo de crónicos de psicosis afectiva se manifestaron disfunciones superficiales, sin comprometer su desempeño en la evaluación de las narraciones. Para el primer episodio de ambas patologías se observó un adecuado desempeño evaluativo del relato. No obstante, en el grupo de esquizofrenia observamos un mayor requerimiento de ayuda por parte del entrevistador para el manejo de los objetivos comunicativos. Tal parece que en la medida en que se deteriora la cognición, las funciones ejecutivas y los sistemas de memoria influyen en el tratamiento que se le da a los eventos recordados; por tanto, a mayor cronicidad, menor control en la construcción narrativa.

d) A pesar de que la variable sexo no reflejó estadísticamente una diferencia entre los participantes, desde una apreciación cualitativa observamos en los hombres un desempeño muy menoscabado en la elicitación de narraciones, en tanto que, entre las mujeres, se mantuvo un funcionamiento ostensiblemente más adecuado. Este hallazgo sugiere que sería necesario indagar desde diversos enfoques esta variable para comprobar si en otro contexto comunicativo es factible distinguir el desempeño entre hombres y mujeres.

e) Es posible que frente a la tarea de elaborar una narración sobre el proceso mórbido vivenciado se debe integrar, por una parte, la situación objetiva, es decir, los hechos, y, por otra, la experiencia subjetiva y su correspondiente evaluación. Las dificultades en la integración pertinente de ambas situaciones son indicadores fiables del deterioro intersubjetivo de la persona que narra. Conducta probada entre los grupos de esquizofrenia en contraste con los de psicosis afectiva de este estudio.

Para finalizar, primero es necesario señalar que el carácter necesariamente limitado de este estudio se superará en la medida que se amplíe el corpus de pacientes de primer episodio de psicosis y que se añadan nuevas pruebas y tareas comunicativas. Revelar con más claridad aspectos disfuncionales en los mismos indicadores que investigamos, o bien en otros que emerjan del trabajo, depende de la observación desde la clínica. En segundo término, la enorme vulnerabilidad de las personas que padecen enfermedades mentales debe motivar esfuerzos por alcanzar formas de intervención basadas en el vínculo y no únicamente en los síntomas, tarea posible en parte con la generación de nuevos dispositivos de evaluación del 
lenguaje desde la Lingüística Clínica y, en parte, con la sistematización de hallazgos a fin de responder a algunos de los innumerables entresijos que persisten en la esquizofrenia cuyo estudio se ha extendido por más de cien años. 


\section{BIBLIOGRAFÍA}

Álvarez Muro, A. (2012): "La poética del habla cotidiana", Estudios de lingüística del español, 32, accesible en: <http://elies.rediris.es/elies32/>.

Andreasen, N. C. y Grove, W. (1986): "Thought, language, and communication in schizophrenia: diagnosis and prognosis”, Schizophrenia Bulletin, 12, págs. 348-359.

Baeza, I., Graell, M., Moreno, D., Castro-Fornielles, J., Parellada, M., GonzálezPinto, A., Parellada, M., González-Pinto, A., Payá, B., Soutullo, C., De la Serna, E. y Arango, C. (2009): "Cannabis use in children and adolescents with first episode psychosis: Influence on psychopathology and short-term outcome (CAFEPS study)", Schizophrenia Research, 113, págs. 129-137.

Bartlet, F. (1932): Remembering, Cambridge, Cambridge University Press.

Bassols, M. y Torrent, A. (2003): Modelos textuales. Teoría y práctica, Barcelona, Octaedro.

Belinchón, M. (1991): Aspectos cognitivos en la esquizofrenia, Madrid, Trotta.

Belli, S., Harré, R. e ÍĨIguez, L. (2010): "Emociones y Discurso: Una mirada a la narrativa científica de la construcción social del amor", Prisma Social, 4, págs. 1-45.

BERMAN, R. y Slobin, D. (eds.) (1994): Relating events narrative crosslinguistics developmental study, Hillsdale, NJ, Lawrence Erlbaum Associates.

Brown, P. y Levinson, S. (1987): Politeness. Some Universals in Language Use. Cambridge, Cambridge University Press.

Brown, G. y Yule, G. (2005): Análisis del discurso, Madrid, Visor.

BRUner, J. (1984): Acción, pensamiento y lenguaje, Madrid, Alianza.

Bruner, J. (2000): Actos de significado, Madrid, Alianza.

Bruner, J. (2003): La fábrica de historias. Derecho, literatura, vida, Buenos Aires, FCE.

CAMARgO, L. (2002): "La narración literaria y la narración en la conversación (la viñeta como recurso motivador de narraciones)", en IV Congreso de Lingüística General, Cádiz, Universidad de Cádiz, vol. 2, págs. 405-416.

CAmargo, L. (2003): "Hacia una definición de la narración oral-conversacional", en Lucía Megías y Cristina Castillo (eds.), Deciamos ayer: estudios en honor a Maria Cruz García de Enterría, Alcalá, Universidad de Alcalá, págs. 43-59.

Castilla del Pino, C. (1991): Aspectos cognitivos en la esquizofrenia, Madrid, Trotta.

Chaika, E. y Lambe, R. (1985): "The Locus of Dysfunction in Schizophrenic Speech”, Schizophrenia Bulletin, 11 (1), págs. 8-15.

Chapman, L. J., Chapman, J. P. y Miller, G. A. (1964): “A theory of verbal behavior in schizophrenia”, en B. A. Maher (ed.), Progress in Experimental Personality Research, New York, Academic press, vol. 1, págs. 49-77.

ChApMAn, L. J. y ChAPMAN, J. P. (1987): "The search for symptoms predictive of schizophrenia”, Schizophrenia Bulletin, 13 (3), págs. 497-503. 
Crow, T. (1997): "Is schizophrenia the price homo sapiens pay for language?”, Schiz Res, 28, págs. 127-141.

DeLISI, L. E. (2001): "Speech disorder in schizophrenia: Review of the literature and exploration of its relation to the uniquely human capacity for language", Schizophrenia Bulletin, 27 (3), págs. 481-496.

DSM-IV (1997): Manual Diagnóstico y Estadístico de los Trastornos Mentales, American Psychiatric Association (SCID-P; Primera et al., 1997a, b).

DSM-V (2014): Manual Diagnóstico y Estadístico de los Trastornos Mentales, American Psychiatric Association.

FERNÁNDEZ, M. (2015): Lingüistica y déficit comunicativos, Madrid, Síntesis.

FigueroA, A. (2015): "Análisis pragmalingüístico de los marcadores de coherencia en el discurso de sujetos con esquizofrenia crónica y de primer episodio", Valladolid, Universidad de Valladolid. Tesis doctoral.

Gallardo Paúls, B. y Valles, B. (2008): "Lingüística en contextos clínicos: la lingüística clínica”, Lengua y Habla, 12, págs. 32-50.

Gallardo Paúls, B. y Hernández Sacristán, C. (2013): Lingüistica Clínica. Un enfoque funcional sobre las alteraciones del lenguaje, Madrid, Arco/Libros.

Georgakopoulou, A. (2007): Small stories, interaction and identities, Amsterdam, John Benjamins.

Goffman, E. (1955): "On Face-Work: An Analysis of Ritual Elements in Social Interaction”, Psychiatry, 18 (3), págs. 213-231.

Goffman, E. (1959): La presentación de la persona en la vida cotidiana, Buenos Aires, Amorrortu.

Goffman, E. (1983): “Interaction Order”, American Sociological Review, 48, págs. $1-17$.

Graesser, A. C., Robertson, S. P. y Anderson, P. A. (1981): "Incorporating inferences in narrative representations: A study of how and why", Cognitive Psychology, 13, págs. 1-26.

Graesser, A., Gernsbacher, M. y Goldman, S. (2000): “Cognición”, en T. A. van Dijk (comp.), El discurso como estructura y proceso. Estudios del discurso: Introducción multidisciplinaria, Barcelona, Gedisa, vol. 1, págs. 417-452.

Guerrero, A. L. (2011): "Narrative as resource for the display of self and identity: The narrative construction of an oppositional identity", Applied Linguistics Journal, 13 (2), págs. 88-100.

Hernández Monsalve, M. (2014): Psicoterapia y rehabilitación de pacientes con psicosis, Madrid, Editorial Grupo.

Holmes, J. (2000): "Narrative in psychiatry and psychotherapy: the evidence?", Journal of Medical Ethics: Medical Humanities, 26, págs. 92-96.

Jimeno Bulnes, N. (2002): "Diagnóstico sindrómico de la esquizofrenia”, Informaciones Psiquiátricas, 169 (3), págs. 315-327.

KAY, S. R., Fiszbein, A. y Opler, L. A. (1987): "The Positive and Negative Syndrome Scale (PANSS) for schizophrenia”, Schizophrenia Bulletin, 13, págs. 261-276.

KinTSCH, W. y VAN DiJK, T. A. (1978): "Toward a model of text comprehension and production”, Psychological Review, 85, págs. 363-394.

Kuperberg, G. (2010): "Language in Schizophrenia, Part 1: An Introduction", Language and Linguistics Compass, 4 (8), págs. 576-589. 
LABOV, W. (1985): "Speech actions and reactions in personal narrative", en D. Tannen (ed.), Analyzing discourse: Text and talk, Washington, DC, Georgetown University Press, págs. 219-247.

LABOv, W. (1997): "Some further steps in narrative analysis", Journal of Narrative and Life History, 7, págs. 395-415.

LAвOv, W. (2006): “Narrative pre-construction”, Narrative Inquiry, 16 (1), págs. $37-45$.

Labov, W. y Fanshel, D. (1977): Therapeutic discourse: Psichotherapy as conversation, New York. Academic Press.

Laguna, E. y Turull, N. (2000): "Aplicaciones del análisis del discurso en rehabilitación psicosocial con pacientes esquizofrénicos”, Revista de Psiquiatría, 27 (4), págs. 193-200.

Levinson, S. (1983): Pragmatics, Cambridge, Cambridge University Press.

LewIs, B. (2011): Narrative Psychiatry: How Stories Can Shape Clinical Practice, Baltimore, The Johns Hopkins University Press.

LuQue, R. y Berríos, G. (2011): "Historia de los trastornos afectivos", Revista Colombiana de Psiquiatría, 40, págs. 130-146.

Mandler, J. M. y Johnson, N. S. (1977): Remembrance of things parsed: Story structure and recall, California, Academic Press.

MANDLER, J. M. (1984): Stories, scripts, and scenes: Aspects of schema theory, Hillsdale, NJ, Erlbaum.

MARCONI, J. (1970): "Una teoría psicopatológica estructural de las psicosis", Acta Psiquiát Psicol. Amér Lat., 16, págs. 5-31.

McGorry, P. D., Yung, A. R. y Phillips, L. J. (2003): "The <close-in> or ultra highrisk model: a safe and effective strategy for research and clinical intervention in prepsychotic mental disorder”, Schizophrenia Bulletin, 29 (4), págs. 771-790.

McKenna, P. J. y OH, Th. (2005): Schizophrenic speech: making sense of bathroots and ponds that fall in doorway, Cambridge, Cambridge University Press.

Mishler, E. (1986): Research interviewing. Context and narrative, Cambridge, Cambridge University Press.

Moreno Fernández, F. (2005): Principios de Sociolingüistica y Sociología del lenguaje, Barcelona, Ariel.

Morice, R. e Ingram, J. (1983): "Language analysis in schizophrenia: Diagnostic implications", Australian and New Zealand J Psychiatry, 16, págs. 11-21.

Prieto, L. y SAn Martín, A. (2002-2003): "Diferencias de género en el empleo del discurso referido: aproximación sociolingüística y pragmático-discursivo”, BFUCh, XXXIX, págs. 269-303.

Rumelhart, D. E. (1975): "Notes on a schema for stories", en D. G. Bobrow y A. M. Collins (eds.), Representation and understanding: Studies in cognitive science, San Diego, CA, Academic Press, págs. 211-236.

Salavera, C. y Puyuelo, M. (2012): "Aspectos semánticos y pragmáticos en personas con esquizofrenia”, Revista de Logopedia, Foniatría y Audiología, 30, págs. 84-93.

SÁnchez, R., Téllez, G. y Jaramillo, L. (2012): "Edad de inicio de los síntomas y sexo en pacientes con trastorno del espectro esquizofrénico", Biomédica, 32 (2), págs. 206-213. 
SCHEGLOFF, E. (1996): "Issues of relevance for discourse analysis: Contingency in action, interaction and co-participant context", en E. H. Hovy y D. R. Scott (eds.), Computational and conversational discourse: Burning Issues - An Interdisciplinary Account, Heidelberg, Springer, págs. 3-38.

SChegloff, E. (1997): "Narrative analysis. Thirty years later", Journal of Narrative and Life Stories, 7 (1-4), págs. 97-106.

Silva Corvalán, C. (2001): Sociolingüistica y pragmática del español, Georgetown University Press.

Tannen, D. (ed.) (1993): Gender and conversational interaction, Oxford, Oxford University Press.

Usall, J. (2003): "Diferencias de género en la esquizofrenia”, Revista de Psiquiatría, 30 (5), págs. 276-287.

VAN DiJK, T. A. (1980): Estructuras y funciones del discurso, México, Siglo XXI.

VAn Dijk, T. A. (1995): "Discourse semantics and ideology", Discourse \& Society, 6 (2), págs. 243-289.

VAn Dijk, T. A. (2006): "Discourse, context and cognition”, Discourse Studies, 8 (1), págs. 159-177.

VARGas, M. (2003): "Posibilidades de rehabilitación neurocognitiva en la esquizofrenia”, Revista de Neurología, 38 (5), págs. 473-482.

WODAK, R. y BENKe, G. (1997): "Gender as a sociolinguistic variable. New perspectives on variation studies", en F. Coulmas (ed.), The Handbook of Sociolinguistics, Oxford, Blackwell, págs. 127-150. 


\section{ANEXO \\ CONVENCIONES DE TRANSCRIPCIÓN CORPUS LEPSI}

Se realizó una transcripción ortográfica de las entrevistas y se incluyeron las siguientes etiquetas propuestas por Gallardo Paúls en el corpus PErLA ${ }^{9}$ :

\begin{tabular}{|l|l|}
\hline \multicolumn{2}{|c|}{ Convenciones de transcripción para este estudio } \\
\hline 0001 & numeración de los turnos de habla \\
\hline$=$ & mantenimiento del turno en un solapamiento \\
\hline$/$ & Pausa corta, de menos de medio segundo \\
\hline$/ /$ & Pausa que oscila entre medio segundo y un segundo \\
\hline$/ / /$ & Pausa de un segundo de duración \\
\hline$(5.0)$ & $\begin{array}{l}\text { Pausa de cinco segundos; se cronometran en casos de especial } \\
\text { relevancia }\end{array}$ \\
\hline- & Guión largo indica pausa en el interior de un turno \\
\hline${ }^{\circ}()^{\circ}$ & Pronunciación en voz muy baja o inaudible \\
\hline MAYÚS & Pronunciación en voz muy alta \\
\hline
\end{tabular}
lencia.

${ }^{9}$ PErLA: Percepción, Lengua y Afasia, corpus de datos clínicos de la Universidad de Va- 